\title{
Immunopathology and the gene therapy of lupus
}

\author{
RA Mageed ${ }^{1}$ and GJ Prud'homme ${ }^{2}$ \\ ${ }^{1}$ Department of Immunology and Molecular Pathology, Royal Free and University College School of Medicine, London, UK; and \\ ${ }^{2}$ Department of Laboratory Medicine and Pathobiology, St Michael's Hospital and University of Toronto, Toronto, Ontario, Canada
}

\begin{abstract}
Lupus is a chronic autoimmune inflammatory disease with complex clinical manifestations. In humans, lupus, also known as systemic lupus erythematosus (SLE), affects between 40 and 250 individuals, mostly females, in each 100000 of the population. There are also a number of murine models of lupus widely used in studies of the genetics, immunopathology, and treatment of lupus. Human patients and murine models of lupus manifest a wide range of immunological abnormalities. The most pervasive of these
\end{abstract}

Keywords: lupus; gene therapy

\section{Introduction}

Lupus is a chronic autoimmune inflammatory disease with complex clinical manifestations. In humans, lupus, also known as systemic lupus erythematosus (SLE), affects between 40 and 250 individuals, mostly females, in each 100000 of the population. ${ }^{1}$ There are also a number of murine models of lupus widely used in studies of the genetics, immunopathology, and treatment of lupus. Human patients and murine models of lupus manifest a wide range of immunological abnormalities. The most pervasive of these are: (1) the ability to produce pathogenic autoantibodies; (2) lack of T- and B-lymphocyte regulation; and (3) defective clearance of autoantigens and immune complexes. The majority of autoantibodies found in lupus are targeted at intracellular nucleoprotein particles, with $98 \%$ of human patients possessing antinuclear antibodies, while antidouble-stranded DNA (dsDNA) antibodies are found in $50-80 \%$ of patients. These latter autoantibodies are thought to be pathogenic and exclusive to lupus. The aetiology of lupus remains unresolved. However, as with most autoimmune diseases, susceptibility involves genetic, environmental, and hormonal factors. These factors cooperate to modify complex relations between the host, pathogens, and the environment. In this article, we briefly review immunological abnormalities and disease mechanisms characteristic of lupus autoimmunity and highlight recent studies on the use of gene therapy to target these abnormalities.

\section{Clinical features}

Virtually all lupus patients manifest joint and/or skin involvement. In addition, the kidneys, heart, lungs, and

Correspondence: Dr RA Mageed, Department of Immunology and Molecular Pathology, The Windeyer Institute, Royal Free and University College London, 46 Cleveland Street, London W1T 4JF, UK are: (1) the ability to produce pathogenic autoantibodies; (2) lack of $T$ - and B-lymphocyte regulation; and (3) defective clearance of autoantigens and immune complexes. This article briefly reviews immunological abnormalities and disease mechanisms characteristic of lupus autoimmunity and highlight recent studies on the use of gene therapy to target these abnormalities.

Gene Therapy (2003) 10, 861-874. doi:10.1038/sj.gt.3302016

the central nervous system (CNS) are involved in about $30-70 \%$ of patients. About $90 \%$ of SLE patients experience generalized arthralgia but with milder inflammation than is seen in rheumatoid arthritis (RA). In all, 60\% of SLE patients complain of myalgia and muscle weakness, and the kidneys are involved in 20-50\% of patients. CNS involvement can affect up to $50 \%$ of patients, where involvement can range from migraine headaches to grand mal seizures. Lymphocytopenia is common and although thrombocytopenia is uncommon, it is a well-recognized complication of lupus. Generally, when SLE involves many organs the prognosis is poor. ${ }^{2}$

\section{Aetiology}

Epidemiologic studies of SLE aetiology have identified three important factors: (1) endocrine-metabolic, (2) environmental, and (3) genetic. The predominance of lupus in females suggests that hormones play a significant role in susceptibility. This is also evident from the rise of sex ratio from 2:1 (female:male) at onset, or at diagnosis, to $6: 1$ at puberty, peaking in young adulthood at $8: 1$, and then declining with female menopause. ${ }^{3}$ Studies of the lupus-prone F1 hybrid mouse, resulting from crossing New Zealand black (NZB) with New Zealand white (NZW) mice (or the BWF1 mouse), implicate a role for female hormones in modulating lymphocyte responsiveness, autoantibody production, development of renal disease, and death. ${ }^{4}$

Environmental factors that cause, or exacerbate SLE include viruses and chemicals. Various studies implicated human retroviruses, especially human T-lymphotropic virus type 1 (HTLV-1) and human immunodeficiency virus (HIV) in lupus. ${ }^{5}$ However, despite several decades of investigation no firm conclusion has been made, although some studies have demonstrated crossreactivity between antibodies to autoantigens such as Ro and Sm found in lupus patients and antibodies to viruses. ${ }^{6}$ 
Other noninfectious environmental factors likely to be involved in lupus include ultraviolet (UV) light and chemicals. In many SLE patients, UV light provokes a photosensitive skin rash that may be followed by a generalized disease flare. The most investigated environmental factors that contribute to SLE are chemicals. The syndrome of drug-induced lupus by hydralazine, procainamide, and isoniazid is well established. ${ }^{7}$ Generally, however, controlled epidemiological studies do not support a role for chemicals in the aetiology of idiopathic SLE.

Evidence for the involvement of genetic factors in susceptibility to lupus is compelling. The number of genetic loci relevant to spontaneous lupus that are identified to date is quite large (see below and also Table 1 ). The general consensus is that environmental agents can cause disease, but only in those individuals who have a permissive genetic background. The importance of genetic factors is evident from studies of twins with SLE, which have revealed that the concordance rate is about $24 \%$ in monozygotic twins, but only $3 \%$ in dizygotic twins. ${ }^{8}$ Studies of human patients and murine models provide evidence for multiple susceptibility genes involving major histocompatibility complex (MHC) and non-MHC loci. Among the many nonMHC-linked loci are genes controlling the pattern of cytokine production and genes that control lymphocyte proliferative responses (Table 1). There is also evidence that complement deficiencies can contribute to disease susceptibility. It is likely, however, that different gene combinations interact with different environmental factors to precipitate disease in different populations. Racial background also appears to have an influence on susceptibility. Thus, although the disease is not restricted to any geographical location, the incidence of SLE is three to eight times higher in Asians and black populations in the Western hemisphere.

\section{Genetics}

Genetic factors are essential elements in susceptibility to lupus. However, no single gene predisposes human patients, or mice, to lupus but rather a combination of different genes contribute to certain aspects of the disease. Thus, each of a relatively large set of genes contributes to hyper-responsiveness and/or lack of regulatory elements, the upregulation of target autoantigens in certain tissues, the combination of which is adequate to result in disease after some environmental stimulus provokes an immune response to nuclear antigens. There is good evidence for this hypothesis in murine lupus. ${ }^{36}$ Adding to the genome of normal mice selected gene segments that predispose to disease in a lupus strain has shown that more than one segment is required to produce clinical disease, and that each has different activity. For example, the gene segment designated sle1 (Table 1), contributes to a breakdown of tolerance to nucleosome, sle2 predisposes to B-lymphocyte hyper-responsiveness, and sle3 provides T-cell hyperactivity. ${ }^{36}$

Genes for the MHC (in humans: human leukocyte antigen; HLA) play a role in susceptibility to lupus. In human patients with lupus, the class II and III regions are particularly important. ${ }^{9-15,37}$ Class II genes, especially

Table 1 Genes associated with predisposition to develop spontaneous lupus disease

\begin{tabular}{|c|c|c|c|}
\hline Gene loci & Species & Immunological effects & Reference \\
\hline $\begin{array}{l}\text { Complement components and receptors: } \\
\text { C1q, C2, C4, CR1, CR2 }\end{array}$ & Human & Inadequate removal of immune complexes and apoptotic bodies & 9 \\
\hline Cytokines: IL-10, IL-6, TNF- $\alpha$ & $\begin{array}{l}\text { Human } \\
\text { and mouse }\end{array}$ & Perturbed lymphocyte functions and lack of regulatory T cells & 10 \\
\hline $\begin{array}{l}\text { Cytokine receptors: } \mathrm{TNF} \alpha-\mathrm{RII}, \mathrm{IL}-4 \mathrm{R}, \mathrm{IFN}-\gamma \\
\text { RI and II }\end{array}$ & Human & Perturbed lymphocyte functions & $11-13$ \\
\hline $\begin{array}{l}\text { MHC class II: DR, DQ (human), I-A, } \\
\text { I-E (mouse) }\end{array}$ & $\begin{array}{l}\text { Human } \\
\text { and mouse }\end{array}$ & Abnormal T-lymphocyte repertoire and autoantibody production & 14,15 \\
\hline TCR: $\alpha, \beta, \gamma$ gene loci & Human & Distorted T-cell repertoire and autoantibody production & 16,17 \\
\hline Ig heavy and light chain gene loci & Human & Skewing of the B-lymphocyte repertoire & 18 \\
\hline IgG Fc receptors: Fc $\gamma \mathrm{II} a$, IIIa, IIIb & Human & Binding of immune complexes to macrophages and lymphocytes & $19-21$ \\
\hline $\begin{array}{l}\text { TCR associated signalling molecules: } \\
\text { TCR } \zeta \text { chain, SHP-1 }\end{array}$ & $\begin{array}{l}\text { Human } \\
\text { and mouse }\end{array}$ & $\begin{array}{l}\text { Defective TC-mediated signalling and function, lymphoproliferation, } \\
\text { autoantibody production }\end{array}$ & $22-24$ \\
\hline $\begin{array}{l}\text { BCR associated signalling molecules: } \\
\text { SHP-1, Fc } \gamma \text { RIIb, Yaa }\end{array}$ & Mouse & $\begin{array}{l}\text { Enhanced B-lymphocyte proliferative responses, autoantibody } \\
\text { production }\end{array}$ & 24,25 \\
\hline Apoptosis: Fas, FasL & Mouse & $\begin{array}{l}\text { Defect in clonal deletion of } \mathrm{T} \text { and B lymphocytes, } \\
\text { lymphoproliferation, autoantibody production }\end{array}$ & 26,27 \\
\hline $\begin{array}{l}\text { Membrane accessory molecules on } \\
\text { lymphocytes: CD } 40 \mathrm{~L}, \mathrm{CD} 22, \mathrm{Fc} \gamma \mathrm{RIIIb}\end{array}$ & $\begin{array}{l}\text { Human } \\
\text { and mouse }\end{array}$ & Excessive lymphocyte proliferative responses & $28-31$ \\
\hline Cell cycle gene: p21 & $\begin{array}{l}\text { Human } \\
\text { and mouse }\end{array}$ & $\begin{array}{l}\text { Accumulation of T-lymphocytes in the G1 phase of the cell cycle, } \\
\text { defective apoptosis }\end{array}$ & 32,33 \\
\hline Nuclease enzymes: Dnase 1 & $\begin{array}{l}\text { Human } \\
\text { and mouse }\end{array}$ & Accumulation of DNA leading to loss of immune tolerance & 34,35 \\
\hline $\begin{array}{l}\text { Genes regulating B- and T-lymphocyte } \\
\text { responses and tolerance to chromatin: } \\
\text { sle1, sle2, sle3 }\end{array}$ & Mouse & $\begin{array}{l}\text { Breakdown of tolerance to chromatin, B-lymphocyte hyper } \\
\text { responsiveness, T-lymphocyte hyper responsiveness and } \\
\text { defective apoptosis }\end{array}$ & 36 \\
\hline
\end{tabular}

The table includes only loci with known linkages with spontaneous lupus in human and murine models of the disease. Genes in knockout and transgenic mice which result in lupus-like phenotype in mice are not included since the relevance of these to idiopathic lupus is not known. 
DR and DQ, influence the autoantibody repertoire, the ability of $\mathrm{T}$ lymphocytes to recognize antigens, the age of onset, and some clinical subsets of disease. HLA-DR2 and -DR3 increase the relative risk for SLE by three folds. HLA-DR2 in some studies is associated with early onset of disease with nephritis, and HLA-DR3 with later onset and dermatitis and less nephritis. In about $5 \%$ of human patients with SLE genes for complement components C1q, C2, and C4 contribute to susceptibility. ${ }^{9}$ Almost all individuals who are homozygous for $\mathrm{C} 1 q$ deficiency develop SLE. In addition, about half of individuals with homozygous deficiency of C2 develop lupus-like diseases, and complete or partial deficiency of $C 4$ predisposes to disease in a minority of individuals. In addition to genes for complement components, polymorphism in the gene encoding tumour necrosis factor alpha (TNF- $\alpha$ ) is associated with SLE. However, despite some early studies suggesting a relation between an allele relating to low synthesis of TNF- $\alpha$ and susceptibility to lupus, further studies failed to identify the underlying relationship between $t n f-\alpha$ gene polymorphism and disease. ${ }^{10}$ In the BWF1 hybrid mouse model of lupus, however, reduced $\mathrm{TNF}-\alpha$ production is associated with disease, and injection of recombinant $\mathrm{TNF}-\alpha$ ameliorates disease. ${ }^{10,38}$ Genes outside the HLA region also predispose to SLE. Most genome scan studies have shown that at least two regions on chromosome 1 increase susceptibility to human lupus. Within one of the regions are genes encoding IgG Fc receptor IIA (Fc $\gamma$ RIIA) and Fc $\gamma$ RIIIA. ${ }^{19}$ The lupus predisposing polymorphisms in these genes relates to poor binding to IgG and phagocytosis of immune complexes. Other genes that have been confirmed as increasing susceptibility to SLE include genes encoding interleukin 10 (IL-10), with risk especially increased when associated with the gene encoding bcl-2, one gene near the $I L-6$ gene, and one gene encoding mannose-binding protein. ${ }^{39}$

Murine models of lupus disease include spontaneous models and knockout mice for single genes, mostly encoding signalling molecules. Knockout and transgenic mice on normal genetic background have helped identify the role of specific genes in the immune system and in autoimmunity. The number and diversity of genes that have resulted in disease features similar to lupus is remarkable and suggest that abnormalities in a large number of genes could lead to lupus autoimmunity. ${ }^{40}$ However, the contribution of such gene defects to human disease is yet to be determined.

Most genetic studies of spontaneous models of lupus have focused on the BWF1, MRL lpr/lpr, and BXSB strains. Lupus autoimmunity in these strains is multigenic, although the MRL lpr/lpr and the BXSB strains have single genes (fas and yaa) that exhibit Mendelian inheritance and contribute to a large proportion of the autoimmune phenotype. Studies of the MRL lpr/lpr strain, and the related variant MRL gld/gld, show that defective apoptosis lead to lupus disease. Although these mice manifest reduced $\mathrm{T}$ helper 1 (TH1) responses, selective expression of Fas in $\mathrm{T}$ cells (under the $l c k$ promoter), but not in B cells, does not affect autoimmunity suggesting that Fas expression in B cells is critical for the development of autoimmunity. ${ }^{41}$ In human patients with SLE, however, the majority of patients do not appear to have mutations in fas or fas ligand. ${ }^{42}$ In the BXSB strain, the yaa gene is responsible for lymphopro- liferation and autoimmunity. Mutations and polymorphisms in other immune-related genes have been shown to predispose to lupus but their exact role remains unclear. These genes include, among others, T-cell receptor (TCR) genes and antibody genes. In the BWF1 strain, predisposition to lupus is strongly linked to MHC class II genes, but clearly other genes are required to develop lupus since the disease does not develop when the predisposing haplotypes are expressed on normal backgrounds. In this strain, the potential importance of TNF- $\alpha$ in lupus is supported by the finding that heterozygous deficiency of TNF- $\alpha$ NZB $\times$ TNF $-/-$ F1 hybrids leads to enhanced autoimmunity and accelerated autoantibody production, hyperproliferating B lymphocytes, and immune complex-mediated renal disease. ${ }^{43}$ Similarly, reduction in TNF- $\alpha$-mediated signalling by gene knockout of TNFR1 resulted in accelerated lymphadenopathy and autoimmune disease in MRL lpr/lpr mice. ${ }^{44}$

\section{Characteristic immunological abnormalities}

Practically, every compartment of the immune system has been reported to be abnormal in lupus. It remains unclear which of the many immunological defects has a causal relation with lupus and which are secondary to the disease process. For example, the production of antilymphocyte autoantibodies in human patients is thought to be secondary to the breakdown of tolerance. Once produced, there is evidence that these antibodies can interact in vivo with subpopulations of lymphocytes, impairing their function. Some of these autoantibody-induced abnormalities may exacerbate the primary defect that initiated the autoantibody production. Under these circumstances, it is difficult to discern which abnormality comes first.

\section{T-lymphocyte and natural killer (NK) cell}

Numerous abnormalities in T-lymphocyte functions have been described in lupus. However, there are no common defects in all human patients. By and large, the presence of autoreactive T-lymphocytes is not thought to reflect a defect in central repertoire generation. Instead, the presence of autoreactive T-lymphocytes reflects a breakdown of tolerance. In murine lupus, one of the dominant abnormalities seen in the early stages of disease is T-lymphocyte hyper-responsiveness. As a result, T-lymphocyte-dependent autoantibodies are produced in high levels, and subsets of these autoantibodies and the immune complexes they form mediate tissue damage. In human patients, there is evidence for reduced numbers of $\mathrm{CD}^{+} \mathrm{T}$ cells, functional defects, and sustained activation. In murine models of lupus there is evidence that intrinsic defects relate to $\mathrm{T}$ lymphocyte hyper-responsiveness. In human patients, however, the underlying factors are more complex. It is possible that a major factor accounting for sustained activation of lymphocytes and the breakdown of selftolerance is the persistence of antigens because of poor clearance and increased apoptosis. ${ }^{9}$

In human patients with lupus, decreased numbers of $\mathrm{T}$, B, and NK cells are common. In T-lymphocyte lymphopenia, certain T-lymphocyte subsets are affected more than others. Many studies reported a reduction in the number of $\mathrm{CD}^{+}$T-lymphocytes. However, other studies indicated decreased numbers of $\mathrm{CD} 4^{+}$cells with 
a naive phenotype in patients with severe nephritis. ${ }^{45}$ At least part of this reduction in the number of T-lymphocytes is attributable to antilymphocyte autoantibodies and partly to increased apoptosis. ${ }^{46}$ Within the $\mathrm{CD}^{+}$and $\mathrm{CD}^{+}$cell subsets, $\mathrm{CD} 28^{+}$cells are decreased in human patients. In addition to decrease in the number of cells, there are known functional abnormalities. Thus, both $\mathrm{CD}^{+}$and $\mathrm{NK}$ cells have decreased cytotoxic activity. ${ }^{47}$ In addition, the ability of these two cell subpopulations to reduce autoantibody production by B-lymphocytes is diminished in lupus. Instead, these two cell populations enhance IgG production in lupus patients. ${ }^{48}$ This abnormality has been attributed, at least partly, to defective production of transforming growth factors beta (TGF- $\beta$ ) ${ }^{49}$ On the other hand, the number of $\mathrm{CD}^{-} \mathrm{CD}^{-}$(double negative) $\mathrm{T}$ lymphocytes, which recognize glycolipid determinants in association with CD1, are increased in lupus patients. These $T$ cells have been associated with increased antiDNA autoantibody production. ${ }^{50}$

In addition to the above-cited defects, T-lymphocytes from human patients and murine lupus have impaired proliferative responses to mitogens, to soluble antigens, and to MHC class II antigens on either allogeneic or autologous antigen-presenting cells. ${ }^{51}$ These defects can be inherent, attributed to persistent activation or antibodies to lymphocytes. In addition, the proliferative response of lupus T-lymphocytes to stimulation through accessory receptors is also reduced. Thus, the proliferative response to anti-CD2 is depressed. ${ }^{51}$ This defective response may be important because signalling through this pathway triggers the TGF- $\beta$-dependent suppressor cell pathway. ${ }^{52}$

There is also evidence for defects in T-lymphocyte signalling. Thus, TCR-mediated signalling has been reported to be either modestly enhanced or normal. ${ }^{53}$ However, other investigators have reported that there is a deficiency in the expression of the zeta chain of the CD3 complex. 22,23 Defects in calcium response to anti-CD3 and mitogen activation in $\mathrm{T}$ cells have also been reported. ${ }^{54}$ Activation of the transcription factor nuclear factor-kappa B (NF- $\kappa \mathrm{B})$, which is crucial for the expression of many genes, is also reported to be abnormal in human patients. ${ }^{55}$ Other abnormally expressed intracellular molecules include protein kinase C (PKC) and CD45. Generation of cAMP in response to multiple different stimuli is also impaired in SLE and protein kinase A (PKA) activity is abnormal in T-lymphocytes from patients with active disease. ${ }^{56}$ More recently, increased binding of a transcriptional inhibitor of IL-2 gene promoter, phosphorylated cAMP response element modifier (pCREM), in lupus $\mathrm{T}$ cells has been shown to underpin reduced IL-2 production. ${ }^{57}$ Further, a defect involving $\mathrm{Cbl}$, an adaptor protein that negatively regulates transmembrane signalling, has been shown. This abnormality has been suggested to underpin persistent hyperexpression of CD40 ligand (CD40L)L and resistance to tolerance induction. ${ }^{58}$

In human and murine models of lupus, there are also known abnormalities in cytokine production by $\mathrm{T}$ lymphocytes. Thus, the level of IL-2 production falls as mice age and disease begins, and in most animal models large quantities of interferon gamma (IFN- $\gamma$ ) and IL-4 are produced. IFN- $\gamma$ drives the production of complement fixing autoantibodies, while IL-4 promotes B-lymphocyte proliferation and thus enhances the production of such autoantibodies. However, in human patients with lupus, cytokine patterns are less predictable. In some patients, disease activity is associated with reductions in lymphocyte production of IL-2, and in most IL-6 levels are high. One of the most consistent observations regarding cytokine production in lupus, which is widely targeted for gene therapy, is the general inability to make TGF- $\beta .^{59}$ Reduction in this cytokine might account for sustained Tand B-lymphocyte hyperactivity possibly owing reduced regulatory T-lymphocytes that require TGF- $\beta$ to mediate their effects.

Based on the above-cited abnormalities in T cells, it is possible to predict that restoration of normal T-lymphocyte functions might correlate with disease remission. In fact, remission with reconstitution of T-cell function has been observed in patients who were treated with oral cyclophosphamide. In these patients, clinical improvement, disappearance of anti-DNA antibodies, normalization of complement, and disappearance of the sequelae of chronic inflammation were followed by normalization of T-lymphocyte proliferation. One case was described in which clinical remission correlated with normalization of IL-2 production, normalization of serum IL-2 receptor level, and increase in $\mathrm{CD}^{+} \mathrm{DR}^{+}$ memory cells. ${ }^{60}$ More recently, a study of anti-IL-10 treatment in human SLE resulted in a decrease in disease activity and improvement in some measures of immune function. ${ }^{61}$ Resetting the immune system in lupus patients with high doses of cyclophosphamide followed by autologous stem cell transplantation has resulted in complete clinical remission and normalization of $\mathrm{T}$ lymphocyte phenotype and repertoire. ${ }^{62}$

\section{B-lymphocytes}

One of the most prevalent immunological abnormalities in lupus is high level of autoantibodies. The structure of these autoantibodies and mechanisms of their production are clearly of importance to disease pathogenesis. Thus, anti-dsDNA autoantibodies bind to nucleosomes, laminin, collagen type IV, and heparan sulphate and can induce nephritis. Although many autoantibodies found in SLE patients are disease markers but not of pathogenic relevance, anti-dsDNA, antiphospholipid, antineuronal, anti-Ro, antierythrocyte, antilymphocytes, and antiplatelet antibodies are likely to participate directly in tissue damage. Intriguingly, antibody responses to immunization are either decreased or normal in lupus patients. ${ }^{63}$ When decreased, primary responses are generally diminished to a greater extent than secondary responses. This suggests that other factors in addition to Blymphocyte hyperactivity may play a role in B-lymphocyte response to self-antigens such as differences in the composition of the target tissues in susceptible mice or human patients with lupus. ${ }^{64}$ There is some evidence for genetic control of antigen expression in target antigens. For example, strains of mice subject to autoimmune myocarditis present different cardiac antigens than do resistant mice. ${ }^{65}$ However, to date, there is no evidence that human patients have different composition of glomerular basement membrane, synovium, or neural tissue, but data regarding difference in beta2-glycoprotein I (B2-gpI) that relate to whether anti-B2-gpI can cause clotting could prove to be an interesting new avenue for investigation. ${ }^{66}$ 
The single most characteristic abnormality investigated in association with autoantibody production in both patients with SLE and in animal lupus models is Blymphocyte hyperactivity. The pathogenic contribution of aberrant T-lymphocyte functions and the local cytokine environment to B-lymphocyte abnormalities are established. However, recent data support a more central pathogenic role for the lupus B lymphocyte itself. For example, lupus-like autoimmunity can ensue with either minimal or no contribution from T-lymphocytes. Thus, polyclonally triggered B-lymphocytes are found in the circulation of patients with SLE and sustained chronic activation of B-lymphocytes in mice leads to the development of autoimmunity. Furthermore, lupusprone mice genetically modified not to have $\mathrm{CD}^{+}{ }^{+}$cells still produce pathogenic autoantibodies. Further, a study by Reininger et $a l^{67}$ showed that transfer of embryonic liver cells from lupus-prone BWF1 mice can lead to antiDNA autoantibody production and sustain lupus-like disease in immunodeficient mice. Genetic as well as functional studies support a role for the lupus Blymphocyte as an independent contributor to the appearance of the disease, apart from the well-known contribution of potentially harmful autoantibody production. Thus, detailed genetic analyses of the lupusprone NZM2410 mouse, which is substrain of the BWF1 mouse, have identified three genetic loci named sle1, sle2, and sle3. ${ }^{36}$ Both sle1 and sle2 genes relate to intrinsic Blymphocyte dysfunction and result in the breakdown of tolerance to chromatin and to hypergammaglobulinemia and IgM autoantibodies. ${ }^{36}$

In human patients with lupus, there is evidence for Blymphocyte hyperactivity and the production of IL-10. However, while the hyperactivity is disease dependent, the ability to produce IL-10 is disease independent, all of which suggest that an intrinsic defect could underlie this abnormality. In addition, B-lymphocytes from patients with SLE and murine lupus manifest phenotypic changes such as aberrant expression of CD40L, CD80, and CD86. ${ }^{68}$ When cultured in vitro, B-lymphocytes from SLE patients spontaneously produce large amounts of immunoglobulins. In contrast, when cultured SLE B lymphocytes are challenged with mitogens, they are found to be markedly deficient in their ability to proliferate further or increase immunoglobulin synthesis, suggesting prior activation. There is also evidence for intracellular signalling abnormalities. Thus, stimulation of blood B-lymphocytes from human patients through their BCR produced significantly higher $\mathrm{Ca}^{+2}$ levels and protein-tyrosine phosphorylation compared with similarly induced responses of B-lymphocytes from patients with other systemic rheumatic diseases or from normals. However, the production of inositol 1,4,5-triphosphate (IP3) was only slightly elevated, raising the possibility of either hyperactive $\mathrm{Ca}^{+2}$ release machinery or of dominant inositol triphosphate-independent pathway $\mathrm{Ca}^{+2}$ release. ${ }^{69}$ In addition, there is evidence for reduced expression of complement receptors 1 and 2 (CR1 and 2), which magnify signalling generated following B-cell receptor (BCR) engagement. ${ }^{70}$ In contrast, there is a reduction in the expression of coreceptors that negatively regulate signalling, such as Fc $\gamma$ RIIb and CD22. ${ }^{19}$ These two receptors assert their inhibitory effects because they bear a signalling inhibitory domain called immunoreceptor tyrosine-based inhibitory motif (ITIM) linked with inhibitory phosphataeses Lyn, Src homology 2-containing tyrosine phosphatase-1 (SHP-1), and SH2 domaincontaining inositol $5^{\prime}$-phosphatase (SHIP). ${ }^{71}$ In the absence of Lyn, the CD22-initiated signalling inhibitory pathways are not triggered. In this respect, a recent study of Lyn expression has shown about two-thirds of patients with SLE have reduced levels of Lyn in their B lymphocytes. ${ }^{72}$

\section{Complement}

Complement deficiency accounts for only about $5 \%$ of all lupus patients but at least $50 \%$ of patients with homozygous deficiencies of the early classical complement pathway develop a lupus-like disease. The increased susceptibility to SLE, associated notably with C1q, C1r, C1s, and C2 deficiency, is thought to be because of impairment of immune complex clearance and solubilization. ${ }^{9,73}$ Deficiency in these components may be partial or complete. Congenital defects in C2 and C4 are often found in patients with MHC haplotypes DR3 and DR2. Homozygous c $4 A$ deficiency occurs in 10-15\% of Caucasian lupus patients despite being rare in the healthy population. Partial $c 4 A$ deficiency occurs in 50$80 \%$ of SLE patients but only in $10-20 \%$ of controls. The level of complement receptors, CR1 and CR2 are also altered in SLE. ${ }^{70}$ CR1, which binds C3b and C4b fragments, is decreased in lupus patients compared with controls and levels correlate with disease activity. In patients with active lupus, CR2 expression is reduced on B-lymphocytes, which may reflect the highly activated status of these cells.

\section{Cytokines}

The earliest identified defect in the cytokine network in lupus is reduction in the production of, and response to, IL-2 in lupus mice. ${ }^{74}$ Subsequent studies of human patients also showed reduced production of IL-2 in vitro following stimulation with antigen or mitogens. ${ }^{75}$ In murine lupus, defect in IL-2 production appears at 4-6 weeks of age in MRL lpr/lpr and BXSB mice, and somewhat later in the BWF1 mouse and becomes more pronounced with disease progression. The cause(s) of this defect is unknown, but several possibilities have been considered. In human patients, impaired TCR signal transduction relating to intrinsic defects in PKC, cAMP, and PKA-1 activity have been suggested. ${ }^{76-78}$ Besides reduced production of IL-2, patients with SLE show a decreased response to IL-2 because of decreased expression of the $\beta$ chain of the receptor compared with T-lymphocytes from normals. ${ }^{79}$ In murine lupus, impaired TCR signalling, IL-2R structural defects, abnormalities in transcription factors, and exhaustion subsequent to excessive and repetitive activation in vivo have been suggested. ${ }^{80}$

The relation between the IL-2 defect in lupus and disease process remains unclear. However, a number of studies have shown that correction of defective Tlymphocyte proliferation and apoptosis in MRL $l p r / l p r$ mice could be achieved in vitro by exogenous IL-2. ${ }^{81}$ Moreover, an early study found reduced serological, cellular, and histological abnormalities of MRL $1 p r / l p r$ mice following infection with a Vaccinia virus-IL2 construct. $^{82}$ Another study reported suppression of nephritis in BWF1 mice treated with anti-IL-2R mAb. ${ }^{83}$ 
Among the many cytokine abnormalities found in lupus mice, one of the most consistent has been high expression of IFN $-\gamma \cdot{ }^{84}$ In human patients, IFN- $\gamma$ may exacerbate or even precipitate SLE. Thus, administration of IFN- $\gamma$ to a patient with RA induced SLE. ${ }^{85}$ In SLE patients, there is evidence for increased serum levels of IFN- $\gamma$ but levels secreted by mitogen-stimulated cells is decreased. ${ }^{86}$ The importance of this cytokine in murine lupus pathogenesis is suggested by the demonstration that BWF1 mice treated with anti-IFN- $\gamma$ antibody, or soluble IFN- $\gamma$ receptor (IFN- $\gamma$ R), during early life significantly delayed disease progression. ${ }^{87,88}$ Overall, these studies suggest that therapeutic interventions with the goal of reducing IFN- $\gamma$ levels in lupus may selectively affect certain pathogenic autoimmune responses without significantly compromising the person's capacity to respond to exogenous antigens.

IL-12, which promotes the expansion and survival of TH1 and NK cells has been reported elevated in the serum of SLE patients compared with normals although there was a great variability within the patients. ${ }^{89}$ Patients with high IL-12 levels also had high levels of IFN- $\gamma$. In contrast, most investigators have found impairment in IL-12 production in patients with SLE. ${ }^{90}$ In lupus mice, an intrinsic defect in the in vitro production of IL-12 by endotoxin-activated macrophages of MRL +/+ and BWF1 mice has been reported. ${ }^{91}$ However, other studies in MRL lpr/lpr mice reported on increased IL-12 production by peritoneal macrophages following stimulation with IFN- $\gamma$ and/or lipopolysaccharide (LPS). ${ }^{92}$ Moreover, daily injections of recombinant IL-12 led to increased serum levels of IFN- $\gamma$ and nitric oxide metabolites, and accelerated glomerulonephritis in the MRL lpr/lpr mouse. These findings suggest that the high production and response to IL-12 by lupus mice may be important in pathogenesis. The addition of IL-12 to SLE peripheral blood mononuclear cells reduced B-lymphocyte functions in vitro including total IgG and anti-dsDNA autoantibody production independent of IFN- $\gamma$ upregulation or downregulation of IL-10. ${ }^{93}$

Increased serum levels of IL-6 have been demonstrated in patients with active SLE compared with patients with inactive disease or healthy controls. ${ }^{94}$ However, others have not been able to document association between IL-6 levels and antibody production or disease activity. ${ }^{95}$ In addition to SLE, high serum levels of IL-6 are found in other conditions such RA, bacterial infections, burns, and alcoholic cirrhosis. ${ }^{96}$ Thus, increased IL- 6 in SLE could be a consequence of response to apoptosis, rather than a participant. $^{97}$ Interestingly, however, an intrinsic abnormality in lupus B-lymphocytes in response to IL-6 has been reported. Thus, while quiescent B-lymphocytes from normal individuals did not respond to IL-6, quiescent B cells from patients with active SLE differentiated into plasma cells without an additional costimulatory signal. ${ }^{98}$ Normal or increased levels of IL-6 have been reported in lupus mice. ${ }^{99}$ Further, administration of recombinant IL-6 to BWF1 mice accelerated glomerulonephritis and caused marked upregulation of mesangial MHC class II antigen and glomerular intercellular adhesion molecule 1 (ICAM-1) expression. ${ }^{100}$ Administration of an anti-IL-6 mAb with anti-CD4 resulted in prevention of autoantibody production, reduced proteinuria, and prolonged survival. ${ }^{101}$
IL-4 levels are reduced in the lupus-prone MRL $1 p r / l p r$ and BWF1 mice, resulting in an increased IFN- $\gamma$ to IL-4 ratio. ${ }^{102}$ However, the role of IL-4 in human patients is unclear. Thus, elevated serum and mRNA levels in PBMCs from SLE patients have been reported. ${ }^{103,104}$ However, the current consensus is that IL-4 production is not increased in SLE patients. ${ }^{105}$ Interestingly, nephritis was completely abrogated in a murine model rendered transgenic for the IL-4 gene under the control of the immunoglobulin heavy chain $(\mathrm{IgH})$ enhancer. $^{106}$

IL-10 is a potent stimulator of B-lymphocyte proliferation and differentiation. It also attenuates macrophage and antigen-presenting cell activation, cytokine production and has both inhibitory and stimulatory effects on Tlymphocytes and, as such, would be expected to play an important role in the immunological abnormalities characteristic of lupus. There are numerous studies showing increased IL-10 production by blood B-lymphocytes and macrophage from SLE patients and increased serum IL-10 levels. This increase in IL-10 is correlated with disease activity and with anti-DNA antibody production. ${ }^{107}$ All murine lupus strains also show increased IL-10 levels, and BWF1 mice repeatedly injected with anti-IL-10 mAb showed substantially delayed onset of autoimmunity. This effect was apparently mediated by upregulation of endogenous TNF- $\alpha$, as the beneficial effect of anti-IL-10 was abolished when antiTNF- $\alpha$ was injected along with the anti-IL-10 antibody. ${ }^{108}$ Conversely, administration of IL-10 accelerated the onset of lupus in these mice. One suggestion from studies of IL-10 in lupus has been that IL-10 promotes disease by increasing Fas/FasL-mediated apoptosis. ${ }^{109}$ Interestingly, there is evidence that while IL-10 normally inhibits monocyte IL-6 production, this is not the case in lupus implying a defect in IL-10-mediated feedback. ${ }^{110}$ This observation suggests that there may be an intrinsic defect in IL-10-induced suppression of cytokine synthesis. This defect may explain the concomitant increase in IL-10 and IL-6 levels and the correlation found between the two cytokines and the polyclonal activation that characterizes lupus. ${ }^{111}$

Additional cytokines have been implicated in lupus pathogenesis, including TNF- $\alpha$, IL- 1 , and TGF- $\beta$. TNF- $\alpha$ was initially shown by Jacob and McDevitt ${ }^{38}$ to be reduced in supernatants of macrophages from BWF1 mice stimulated with LPS compared with nonautoimmune strains and repeated injections of recombinant TNF- $\alpha$ from the age of 4 months delayed proteinuria and death in these mice. In human patients, stimulated blood mononuclear cells from patients who are DQw1 and $\mathrm{DR}^{+}$produce lower amounts of TNF- $\alpha$ than DR3- and DR4-positive individuals. Furthermore, the DR2, DQw1, and DR3 are strongly associated with SLE. ${ }^{112}$ It has been suggested that the true association is with TNF- $\alpha$ since this gene is located in MHC class III region close to HLADR on the same chromosome. However, the association of a polymorphic variant reportedly associated with low TNF- $\alpha$ production by macrophages is controversial. ${ }^{113,114}$ Exactly how TNF- $\alpha$ might affect lupus is unclear at present. However, studies of the BWF1 mouse by Jacob and McDevitt and by Ishida and colleagues showed that administration of $\mathrm{TNF}-\alpha$ to adult mice ameliorates disease. ${ }^{38,108}$ Two possibilities can be envisaged; the first is reduced responsiveness of autoreactive T-lympho- 
cytes $^{115}$ and second increased TGF- $\beta$ production by regulatory T cells. ${ }^{49}$

Increased spontaneous production of IL-1 by monocytes from lupus patients was reported in the 1980 s. ${ }^{116}$ In contrast to increased spontaneous production, the ability of monocytes to produce detectable levels of IL-1 after stimulation is decreased in most patients with SLE. ${ }^{117}$ Increased IL-1 levels have also been described in lupusprone mice. ${ }^{84}$ Recombinant IL-1 given to BWF1 mice increased nephritis, ${ }^{118}$ while recombinant IL-1R type I given to MRL lpr/lpr mice inhibited nephritis and autoantibody levels in one study. ${ }^{119}$

The production of lymphocyte-derived TGF- $\beta$, in both its latent and active forms is, decreased in patients with SLE. ${ }^{49}$ Further, decreased production of total TGF- $\beta$, but not active TGF- $\beta$, is associated with disease activity. Studies of TGF- $\beta$ regulation revealed that IL- 2 and TNF- $\alpha$ increased the production of active TGF- $\beta$, whereas IL-10 had the opposite effect. Further, blocking IL-10 with antibody increased the levels of TGF- $\beta$. This blocking of IL-10 led to increased active TGF- $\beta$ production adequate to enable $\mathrm{CD}^{+}$T-lymphocytes to develop inhibitory activity. ${ }^{120}$ Male BXSB and MRL lpr/lpr mice show increased levels of TGF- $\beta$, which was shown in MRL lpr/lpr mice to adversely affect host defence against both Gram negative and positive bacterial infections because of the failure of initial polymorphonuclear leucocyte migration to infection sites. ${ }^{121}$ The findings that blocking IL-10 in lupus increases lymphocyte-derived TGF- $\beta$ and restores regulatory $\mathrm{T}$-lymphocyte activity suggest that the potential exists for correcting pathogenic immunoregulatory defects in vivo by targeting the cytokine network.

\section{Phagocytosis}

Both human patients and murine models of lupus exhibit defective clearance of immune complexes. The defects are complex but the role of the Fc $\gamma$ receptors and CR1 in clearing immune complexes has been widely studied because of observations that alleles of Fc $\gamma$ RIIa that do not bind IgG well predispose to lupus. ${ }^{19}$ In addition, consumption or mutations in CR1 alleles also increase the risk for lupus. In addition to abnormality in removal of immune complexes, the crosslinking of Fc $\gamma R$ on the receptor of B-lymphocytes, which acts as a negative feedback mechanism, is abnormal in lupus. This abnormality could result from defective $F_{c} \gamma R$, defective signalling, or the presence of a second signal on cell surfaces that programme the cell for activation rather than death.

\section{Gene therapy for the treatment of lupus}

As cited above, lupus is associated with a wide range of immunological abnormalities. Attempts at developing specific biological therapies have targeted a number of these defects using recombinant cytokines, blocking antibodies, and soluble receptors. With the recent advance in establishing protocols for gene therapy of a number of animal models of autoimmune diseases, gene therapy has become an obvious strategic approach to treat lupus disease. Gene therapy is an efficient and advantageous way of delivering immunomodulators and anti-inflammatory mediators, which include naturally occurring or genetically engineered inflammatory cytokine inhibitors (anticytokines), or potent anti-inflammatory cytokines such as TGF- $\beta 1$. Protective effects have been observed in several autoimmune/inflammatory disorders by transfer of cDNA encoding IL-1 receptor antagonist (IL-1Ra), soluble IFN- $\gamma \mathrm{R} / \mathrm{IgG}-\mathrm{Fc}$ fusion protein, TNF- $\alpha$ receptor (TNFR), or TGF- $\beta 1 .^{122}$

The inflammatory cytokines IL-12 and IFN- $\gamma$ have been found to mediate tissue injury in both organspecific and systemic autoimmune diseases. These cytokines are usually produced in TH1-mediated responses, such as delayed-type hypersensitivity (DTH). As cited above, defects in the production, or response to these inflammatory cytokines, contribute to the pathogenesis of lupus. Similar observations have been made in other autoimmune diseases. For instance, in nonobese diabetic (NOD) mice with autoimmune diabetes (type I diabetes), inflammation of islets of Langerhan's (insulitis) is associated with in situ IL-12 and IFN- $\gamma$ production, and disease can be adoptively transferred with some islet cell-reactive TH1 clones. Therefore, investigators have sought to prevent autoimmune diseases by blocking the action of these inflammatory cytokines. ${ }^{123}$ As alluded to above, this has frequently been accomplished with monoclonal antibodies (mAbs). However, in practice this has proven problematic for several reasons. These proteins must be repeatedly administered by parenteral routes, which are a major therapeutic inconvenience, and they can be neutralized by the host immune response. In the case of anti-inflammatory cytokines, a short half-life $\left(T_{1 / 2}\right)$ and toxic effects (especially after bolus administration) are often major limitations to their therapeutic use.

Gene therapy obviates some of these limitations. Somatic gene therapy makes long-term, constant systemic delivery of many protein mediators feasible. Tissue-localized delivery can also be achieved, such as in joints or the CNS. Moreover, genes can be transduced into autoantigen-specific T-lymphocytes that can home into a target organ. Despite its promise, however, gene therapy is a young field and a variety of questions must be addressed.

\section{TGF- $\beta 1$, a potent anti-inflammatory cytokine}

The most potent anti-inflammatory cytokine is TGF- $\beta 1$, although IL-4, IL-10, and IL-13 have some similar effects, particularly through their action on macrophages. There is a vast literature on the immunobiology of TGF- $\beta{ }^{124}$ and only major points are mentioned here. At least three TGF- $\beta$ isoforms exist in mammals, but TGF- $\beta 1$ is the principal type produced by cells of the immune system. It is secreted in a latent form where mature TGF- $\beta 1$ is associated with a precursor peptide (latency associated peptide (LAP)) and latent TGF- $\beta 1$-binding protein (LTBP). The active form can be generated in vitro by acidification of this complex, and is probably released in vivo through the action of plasmin and other proteases in inflammatory or other sites, although the mechanism is not fully elucidated. TGF- $\beta 1$ receptors are expressed by almost all cells and, interestingly, this cytokine also binds to several matrix components in tissue.

TGF- $\beta 1$ is produced by T-lymphocytes (some called regulatory or TH3 cells), macrophages, and many other cell types in various tissues. It exerts diverse immuneinhibitory effects on B-lymphocytes, $\mathrm{CD}^{+}$T-lympho- 
cytes (TH1 or $\mathrm{TH} 2), \mathrm{CD}^{+}$cytotoxic T-lymphocytes (CTLs), NK cells, lymphokine-activated killer (LAK) cells, and macrophages. In macrophages, TGF- $\beta 1$ antagonizes the activities of IFN- $\gamma$ and TNF- $\alpha$, and inhibits inducible nitric oxide synthase (iNOS) activity. This cytokine also alters expression of E-selectin and other adhesion molecules, and interferes with the adhesion of neutrophils and lymphocytes to endothelial cells. The potent immunosuppressive effects of TGF- $\beta 1$ are most clearly demonstrated in studies of TGF- $\beta$ knockout mice, which die rapidly from a systemic inflammatory syndrome.

TGF- $\beta 1$ has fibrinogenic and immunosuppressive effects that can be detrimental, since overproduction has been associated with pulmonary fibrosis, glomerulopathy, scleroderma, chronic graft-versus-host disease, and impaired immunity against infectious agents and tumours. ${ }^{121}$

\section{Anti-inflammatory cytokine gene therapy}

Administration of TGF- $\beta 1$ is protective in several inflammatory conditions. In mice, microgram amounts of either active or latent protein are required to achieve immunosuppressive effects. ${ }^{125,126}$ Recently, several investigators examined gene therapy approaches of delivery. Intramuscular (i.m.) injection of naked plasmid DNA encoding latent TGF- $\beta 1$ ( $p C M V-T G F-\beta 1)$ increased circulating levels of this cytokine by several folds, suppressed DTH, and protected against autoimmune lesions. ${ }^{127,128}$ In most cases, a latent TGF- $\beta 1$ gene has been administered, and it is quite clear that the cytokine is activated in vivo, although the mechanism has not been established. Based on the literature, it is possible to suggest that at least part of the circulating TGF- $\beta 1$ is activated at sites of inflammation, perhaps through the action of macrophages or other lymphoid cells. The administration of a modified active form of the TGF- $\beta 1$ gene is feasible, but since virtually all cells have receptors it seems undesirable to deliver that form. A large proportion of the TGF- $\beta 1$ molecules would not reach their intended target and, furthermore, adverse effects would be more likely to occur.

Raz and co-workers ${ }^{127,129}$ showed that direct injections of cDNA expression plasmids encoding IL-2, IL-4, or latent TGF- $\beta 1$ into mouse skeletal muscle induce biological effects characteristic of these cytokines. Mice injected intramuscularly with a vector encoding IL-2 enhanced humoral and cellular immune responses to an exogenous antigen, transferrin, which was delivered at a separate site. These IL-2 effects were abolished by coadministration of a vector directing synthesis of TGF$\beta 1$. The TGF- $\beta 1$ vector by itself depressed the antitransferrin antibody response and caused an eight-fold increase in plasma TGF- $\beta 1$ activity. The TGF- $\beta 1$ plasmid injection did not cause muscle infiltration with monocytes or neutrophils and there was no evidence for fibrotic changes.

Monthly injections of TGF- $\beta 1$ plasmid DNA into MRL lpr/lpr mice between 6 and 26 weeks of age increased survival to $70 \%$ of the treated mice at 26 weeks compared with $40 \%$ in the control group, decreased antichromatin and rheumatoid factor antibodies and induced a 50\% decrease in total IgG production. Renal function was improved with reduced blood urea nitrogen (BUN) levels and kidney inflammation as estimated by a histological score. Those beneficial effects occurred in the apparent absence of local or systemic side effects. In contrast, injection of IL-2 cDNA was harmful with a decreased survival to $20 \%$ at 26 weeks, enhanced total IgG synthesis and autoantibody production with a 4.5fold increase in antichromatin antibodies. ${ }^{129}$

However, not all investigators have found IL-2 to be detrimental in lupus. For example, Gutierrez-Ramos et $a l^{82}$ observed a beneficial effect for IL-2 on the disease progression in MRL $l p r / l p r$ mice using live vaccinia recombinant viruses expressing human IL-2 gene. Vaccinated mice showed prolonged survival, decreased autoantibody titres, marked attenuation of kidney interstitial infiltration, and intraglomerular proliferation, as well as clearance of synovial mononuclear infiltrates. Inoculation with the IL-2/vaccinia recombinant virus led, in addition, to drastic reduction of the doublenegative T-lymphocyte population observed in these mice, improved thymic differentiation and restoration of normal values of mature cells in peripheral lymphoid organs. A caveat is that immune responses to vaccinia antigens could have altered the immune system and contributed to this beneficial effect. Indeed, the use of strongly antigenic viral vectors is a serious limitation for immunological studies.

Huggins et al 130,131 also investigated the effects of IL-2 and TGF- $\beta$ gene therapy on the progress of autoimmune disease in MRL $l p r / l p r$ mice with a different approach. The mice were treated orally with a nonpathogenic strain of Salmonella typhimirium bearing the aroA-aroD-mutations and carrying the murine genes encoding IL-2 and TGF- $\beta$. The bacteria synthesize and slowly release the cytokines in vivo. Their results showed that, contrary to expectations, TGF- $\beta$ gene therapy produced no improvement in pathology and generally had opposite effects to those of IL-2. IL-2 gene therapy restored the defective Tlymphocyte proliferative response to mitogen and suppressed the autoantibody response, nephritis, and growth of lymphoid tumours. With this approach, it is unclear to what extent the cytokines enter lymphoid tissues and/or the circulation, and how immunological effects are mediated. Therefore, these results must be interpreted with caution, and are difficult to compare with those obtained by other methods of delivery.

These contradictory results highlight the risks inherent in using cytokines as therapeutic molecules. Most cytokines have complex pleiotropic actions, and may have stimulatory or inhibitory effects depending on their concentration, target tissue or cell, as well as interacting cytokines in the extracellular milieu. Thus, cytokines that are generally thought of as anti-inflammatory, such as TGF- $\beta 1$, sometimes have inflammatory effects. ${ }^{124}$ Similarly, proinflammatory cytokines, such as IL-12, are sometimes, paradoxically, protective. For instance, Hagiwara and colleagues found that administering a DNA plasmid encoding IL-12 to MRL $l p r / l p r$ mice significantly inhibited lymphadenopathy and splenomegaly. ${ }^{132} \mathrm{~A}$ significant decrease in serum IgG anti-DNA autoantibody titres was observed, and plasmid IL-12 therapy was also associated with a reduction in the proteinuria and nephritis. Serum IFN- $\gamma$ level was increased by inoculating the IL-12 encoding plasmid, suggesting that the cytokine balance was skewed towards a TH1-type response. This is surprising, since other investigators found that neutralizing IFN- $\gamma$ is protective in this 
disease $^{87,88}$ (also see below). It may be that this plasmid also induced the production of regulatory cytokines that counterbalanced inflammatory cytokines.

\section{Gene therapy with CTLA-4/lg}

An alternative approach to using inhibitory cytokines involves blocking costimulation with molecules such as cytotoxic T-lymphocyte antigen 4-Ig (CTLA-4/Ig) recombinant protein that mask a T-cell stimulatory molecule, or its ligand. CTLA-4/Ig binds to B7-1 and B7-2 with high affinity and inhibits the provision of stimulatory signals through B7/CD28 interactions. ${ }^{133}$ Indeed, CTLA-4/Ig has been intensely studied as an immunosuppressive molecule, particularly in transplant recipients. ${ }^{134}$ Gene therapy using this approach has also been shown to be beneficial in the MRL lpr/lpr lupus mice. ${ }^{135}$ These investigators demonstrated that systemic administration of a soluble form of CTLA-4/IgG prevented the autoantibody-mediated pathology in the MRL lpr/lpr mouse. To test the potential protective effects of CTLA4/IgG gene delivery on the development of lupus nephritis, these investigators injected MRL lpr/lpr mice with a recombinant adenovirus vector containing CTLA-4/IgG gene. ${ }^{135}$ They observed that a single administration of intravenous injection of AdCTLA-4/IgG into MRL lpr/lpr mice resulted in almost complete suppression of nephritis.

\section{Gene therapy with cytokine inhibitors}

Compared with cytokines, cytokine inhibitors (such as antibodies or soluble receptors) are advantageously nontoxic and often long-lived in body fluids. Transfer of cDNA encoding these molecules protects against several autoimmune diseases. ${ }^{122}$

Prud'homme and co-workers ${ }^{136-138}$ constructed an expression plasmid encoding IFN- $\gamma \mathrm{R} / \mathrm{IgG} 1-\mathrm{Fc}$ fusion proteins. The appropriate murine cDNA segments were inserted into the plasmid VR-1255 (abbreviated as VR; Vical Inc., San Diego, CA, USA), which is exceptionally effective in muscle. ${ }^{139}$ It has a cytomegalovirus (CMV) IE-EP, CMV intron A, and a rabbit beta-globin transcriptional terminator. COS-7 cells transfected with these plasmids secreted IFN- $\gamma \mathrm{R} / \mathrm{IgG} 1-\mathrm{Fc}$ fusion protein in vitro as a disulphide-linked homodimer, with the expected biological activity. ${ }^{111}$ Thus, IFN- $\gamma$ R/IgG1-Fc neutralized IFN- $\gamma$-dependent NO production by macrophages (stimulated with IFN- $\gamma+\mathrm{LPS}$ ). Intramuscular (i.m.) injections $(100 \mu \mathrm{g}$ naked DNA/muscle into two muscles, administered twice) of the IFN- $\gamma \mathrm{R} / \mathrm{IgG} 1-\mathrm{FC}_{\mathrm{C}}$ plasmid in mice resulted in IFN- $\gamma \mathrm{R} / \mathrm{IgG} 1-\mathrm{Fc}$ serum levels exceeding $100 \mathrm{ng} / \mathrm{ml}$ for months after treatment. ${ }^{136,137}$ Higher levels ( $>200 \mathrm{ng} / \mathrm{ml}$ ) were produced by repeated DNA injections. The high-level and long-term expression of this vector, compared with many other plasmid vectors, may be related to the neutralization of IFN- $\gamma$, since this cytokine can suppress transcription promoted by CMV IE-EP elements.

In vivo, administration of the IFN $\gamma \mathrm{R} / \mathrm{IgG} 1-\mathrm{Fc}$ construct almost completely blocked systemic IFN- $\gamma$ activity induced by either low-dose streptozotocin (in CD-1 or C57BL/6 mice) or cyclophosphamide (in NOD mice). Moreover, this plasmid was protective in either spontaneous, or drug-induced models of autoimmune diabetes, in accordance with the postulated pathogenic role of IFN- $\gamma$. Interestingly, IFN- $\gamma \mathrm{R} / \mathrm{IgG} 1-\mathrm{Fc}$ gene therapy protected NOD mice better than IFN- $\gamma$ gene knockout. The reason is unclear, but mice deficient in IFN- $\gamma$ from foetal life may develop compensatory mechanisms.

As cited above, wide ranging abnormalities in the cytokine network have been reported in lupus, but increased levels of IFN- $\gamma$ in serum, lymphoid organs and inflamed tissues is one of the most prominent. ${ }^{84,140}$ Lawson and co-workers ${ }^{137,141}$ inoculated an IFN- $\gamma \mathrm{R} /$ IgG1-Fc plasmid into MRL lpr/lpr mice and observed low-level expression compared with a previous study in NOD and CD1 mice with the same vector. However, serum IFN- $\gamma$ levels of untreated MRL $l p r / l p r$ mice are very high. It is likely that the level of the soluble receptor was low in MRL lpr/lpr mice because it was removed after binding to IFN- $\gamma$. Alternatively, residual IFN- $\gamma$ might have shut down the vector's CMV immediate/ early enhancer promoter that is known to be sensitive to this cytokine.

When in vivo electroporation was applied to enhance gene transfer in MRL lpr/lpr mice, serum IFN- $\gamma$ R/IgG1Fc levels, which had been $<10 \mathrm{ng} / \mathrm{ml}$ without electroporation, exceeded $100 \mathrm{ng} / \mathrm{ml}$ and, consequently, IFN- $\gamma$ serum levels were markedly reduced. ${ }^{141}$ Thus, electroporation was remarkably effective, and it is likely that this technique will be even more relevant to other species. Indeed, in primates and other large mammals i.m. gene transfer of naked DNA is not as efficient as in rodents, but is greatly augmented by in vivo electroporation. ${ }^{142}$

Treatment with the IFN- $\gamma \mathrm{R} / \mathrm{IgG} 1$ plasmid by i.m. injections, especially with electroporation, protected MRL lpr/lpr mice from early death, and reduced autoantibody titres, renal disease, and histological markers of lupus-like disease. ${ }^{141}$ Most notably, when therapy was initiated in 4-month-old diseased mice, survival was extended beyond expectations, with $100 \%$ of the mice staying alive at 14 months of age compared with none in the control group. Remarkably, disease severity was reduced or even suppressed in the treated group.

The mechanism(s) by which IFN- $\gamma$ contributes to the pathogenesis of lupus is not clear, but there are important clues. IFN- $\gamma$ promotes production of complement-fixing autoantibodies of the IgG2a and IgG3 isotypes. In addition, IgG3 has cryogenic properties. Furthermore, IFN- $\gamma$ enhances several pathogenic activities of macrophages and promotes inflammation in target tissues.

Other investigators have attempted to neutralize IFN- $\gamma$ in mouse lupus models using polyclonal antibodies and mAbs, as well as soluble IFN- $\gamma$ R. These approaches, however, have limitations: for example, large quantities of mAbs would be required and may not achieve sufficient concentration in tissues to be effective, and/ or they may be neutralized by the host immune response. With regard to soluble recombinant receptors, rapid turnover may affect efficacy and necessitates repeated administration. These constraints might explain the previously reported negative results of anti-IFN- $\gamma$ $\mathrm{mAb}$ treatment of MRL lpr/lpr mice, and the finding that treatment with recombinant soluble IFN- $\gamma \mathrm{R}$ in BWF1 mice was effective only when initiated early, but not late, when IFN- $\gamma$ levels are significantly higher. ${ }^{88}$

The IFN- $\gamma \mathrm{R} / \mathrm{IgG1}-\mathrm{Fc}$ fusion protein produced in these studies is comprised of segments of endogenous murine proteins. Antibodies reactive with these proteins do not 
appear to be produced in treated mice, even after repeated injections of plasmid over several weeks. ${ }^{136} \mathrm{In}$ this respect, it appears that plasmids that do not encode immunogenic proteins, or plasmids injected into immunodeficient SCID mice, are expressed for longer periods. This may be related to the fact that myocytes encoding xenogeneic proteins can be attacked and killed by the immune system, as observed in DNA vaccination studies, and/or because locally produced IFN- $\gamma$ inhibits the vectors' promoters.

The addition of an IgG Fc segment to a therapeutic protein is not always essential, but may confer significant advantages. The Fc portion of IgG simplifies purification of the recombinant protein by affinity chromatography, and the increase in size can prolong the half-life of small proteins in body fluids. For instance, the half-life of the truncated IFN- $\gamma$ receptor is quite short compared with a receptor/Fc fusion protein. Also, dimers are likely to have a higher avidity for their ligand, as is clearly the case with the IFN- $\gamma$ receptor.

\section{Conclusions and future prospects}

The gene therapy of lupus is still in its infancy, and there are only a limited number of reported studies in the literature. Unlike using proteins for therapy, gene therapy allows long-term and relatively constant delivery of many cytokines, or cytokine inhibitors at therapeutic levels even after one, or a few injections. Viral and nonviral vectors have been used to protect against organ-specific and systemic autoimmune diseases in several models. TGF- $\beta 1$ gene therapy has been reported to suppress murine lupus as well as several other autoimmune (and/or inflammatory) diseases. Similarly, soluble IFN- $\gamma \mathrm{R} / \mathrm{IgG}-\mathrm{Fc}$ ameliorates both lupus and type I diabetes.

Viral vectors are efficient for gene delivery, but have some limitations for immunological studies, because they can provoke inflammation making readministration of the vector difficult since they can trigger host immune responses. Intramuscular injection of naked DNA usually generates relatively low levels of circulating cytokines but this is often an advantage, since most cytokines are active at very low levels, while high levels can be toxic. These vectors can also stimulate inflammation through bacterial CpG-containing immunostimulatory sequences that bind to Toll-like receptor 9 (TLR9), ${ }^{143}$ but this is not antigen-specific and frequent readministration of the vector is possible. When higher levels of expression are desired, as with cytokine inhibitors, this can be accomplished by applying in vivo electroporation.

The delivery of inhibitory soluble cytokine receptors, or other cytokine inhibitors, has significant advantages over other methods. The neutralization of IFN- $\gamma$ using its soluble receptor is particularly effective in murine lupus. IFN- $\gamma \mathrm{R}$ has no direct toxic or adverse effects other than suppressing immunity, but only as related to the neutralization IFN- $\gamma$. Most, if not all, immunosuppressive drugs have many adverse effects and much broader suppressive activity. Cytokines can be blocked with mAbs, but even humanized immunoglobulins can give rise to neutralizing immune responses in the recipient. In contrast, soluble receptors made only of self-elements are much less likely to be neutralized. Many tools are now available to the immunologist, at least experimentally, to treat autoimmune/inflammatory diseases, but few are as promising as the gene therapy approaches.

\section{Acknowledgements}

RA Mageed is supported by grants from Arthritis Research Campaign, UK. The studies of GJ Prud'homme described in this review were supported by the Juvenile Diabetes Research Foundation International, the Canadian Diabetes Association, the National Cancer Institute of Canada, and in collaboration with Dr AN Theofilopoulos of the Scripps Research Institute, La Jolla, CA by NIH Grants AR31203, AG15061, and AR39555. We thank Vical Inc. (San Diego, CA) for providing the VR1255 expression plasmid used in some of the studies described in the review.

\section{References}

1 Michet Jr CJ et al. Epidemiology of systemic lupus erythematosus and other connective tissue diseases in Rochester, Minnesota, 1950 through 1979. Mayo Clin Proc 1985; 60: 105-113.

2 Hochberg MC. Updating the American College of Rheumatology revised criteria for the classification of systemic lupus erythematosus. Arthritis Rheum 1997; 40: 1725.

3 Masi AT, Kaslow RA. Sex effects in systemic lupus erythematosus: a clue to pathogenesis. Arthritis Rheum 1978; 21: 480-484.

4 Roubinian JR et al. Effect of castration and sex hormone treatment on survival, anti-nucleic acid antibodies, and glomerulonephritis in NZB/NZW F1 mice. J Exp Med 1978; 147: 15681583.

5 Pincus T. Studies regarding a possible function for viruses in the pathogenesis of systemic lupus erythematosus. Arthritis Rheum 1982; 25: 847-856.

6 Hardgrave KL, Neas BR, Scofield RH, Harley JB. Antibodies to vesicular stomatitis virus proteins in patients with systemic lupus erythematosus and in normal subjects. Arthritis Rheum 1993; 36: 962-970.

7 Yung RL, Richardson BC. Drug-induced lupus. Rheum Dis Clin North Am 1994; 20: 61-86.

8 Deapen $\mathrm{D}$ et al. A revised estimate of twin concordance in systemic lupus erythematosus. Arthritis Rheum 1992; 35: 311-318.

9 Walport MJ. Complement and systemic lupus erythematosus. Arthritis Res 2002; 4 (Suppl 3): S279-S293.

10 O'Shea JJ, Ma A, Lipsky P. Cytokines and autoimmunity. Nat Rev Immunol 2002; 2: 37-45.

11 Tsuchiya $\mathrm{N}$ et al. New single nucleotide polymorphisms in the coding region of human TNFR2: association with systemic lupus erythematosus. Genes Immun 2000; 1: 501-503.

12 Kanemitsu S et al. Association of interleukin-4 receptor and interleukin-4 promoter gene polymorphisms with systemic lupus erythematosus. Arthritis Rheum 1999; 42: 1298-1300.

13 Nakashima $\mathrm{H}$ et al. The combination of polymorphisms within interferon-gamma receptor 1 and receptor 2 associated with the risk of systemic lupus erythematosus. FEBS Lett 1999; 453: 187190.

14 Schur PH. Genetics of systemic lupus erythematosus. Lupus 1995; 4: 425-437.

15 Ibnou-Zekri N et al. MHC-linked control of murine SLE. Curr Top Microbiol Immunol 1999; 246: 275-280.

16 Tebib JG, Alcocer-Varela J, Alarcon-Segovia D, Schur PH. Association between a $\mathrm{T}$ cell receptor restriction fragment length polymorphism and systemic lupus erythematosus. J Clin Invest 1990; 86: 1961-1967. 
17 Frank MB, McArthur R, Harley JB, Fujisaku A. Anti-Ro(SSA) autoantibodies are associated with $\mathrm{T}$ cell receptor beta genes in systemic lupus erythematosus patients. J Clin Invest 1990; 85: 3339.

18 Olee $\mathrm{T}$ et al. Molecular basis of an autoantibody-associated restriction fragment length polymorphism that confers susceptibility to autoimmune diseases. J Clin Invest 1991; 88: 193-203.

19 Salmon JE et al. Fc gamma RIIA alleles are heritable risk factors for lupus nephritis in African Americans. J Clin Invest 1996; 97: 1348-1354.

20 Zuniga $\mathrm{R}$ et al. Low-binding alleles of Fcgamma receptor types IIA and IIIA are inherited independently and are associated with systemic lupus erythematosus in Hispanic patients. Arthritis Rheum 2001; 44: 361-367.

21 Hatta Yet al. Association of Fc gamma receptor IIIB, but not of FC gamma receptor IIA and IIIA polymorphisms with systemic lupus erythematosus in Japanese. Genes Immun 1999; 1: 53-60.

22 Tsokos GC, Liossis SN. Immune cell signaling defects in lupus: activation, anergy and death. Immunol Today 1999; 20: 119-124.

23 Liossis SN, Ding XZ, Dennis GJ, Tsokos GC. Altered pattern of TCR/CD3-mediated protein-tyrosyl phosphorylation in T cells from patients with systemic lupus erythematosus. Deficient expression of the T cell receptor zeta chain. J Clin Invest 1998; 101: 1448-1457.

24 Shultz LD et al. Mutations at the murine motheaten locus are within the hematopoietic cell protein-tyrosine phosphatase (Hcph) gene. Cell 1993; 73: 1445-1454.

25 DesJardin LE, Butfiloski EJ, Sobel ES, Schiffenbauer J. Hyperproliferation of BXSB B cells is linked to the Yaa allele. Clin Immunol Immunopathol 1996; 81: 145-152.

26 Watanabe-Fukunaga $\mathrm{R}$ et al. Lymphoproliferation disorder in mice explained by defects in Fas antigen that mediates apoptosis. Nature 1992; 356: 314-317.

27 Takahashi $\mathrm{T}$ et al. Generalized lymphoproliferative disease in mice, caused by a point mutation in the Fas ligand. Cell 1994; 76: 969-976.

28 Desai-Mehta A, Lu L, Ramsey-Goldman R, Datta SK. Hyperexpression of CD40 ligand by B and T cells in human lupus and its role in pathogenic autoantibody production. I Clin Invest 1996; 97: 2063-2073.

29 Lettesjo H, Burd GP, Mageed RA. CD4+ T lymphocytes with constitutive CD40 ligand in preautoimmune $(\mathrm{NZB} \times \mathrm{NZW}) \mathrm{F} 1$ lupus-prone mice: phenotype and possible role in autoreactivity. J Immunol 2000; 165: 4095-4104.

30 Mary C et al. Dysregulated expression of the Cd22 gene as a result of a short interspersed nucleotide element insertion in Cd22a lupus-prone mice. J Immunol 2000; 165: 2987-2996.

31 Jiang $\mathrm{Y}$ et al. Genetically determined aberrant down-regulation of FcgammaRIIB1 in germinal center B cells associated with hyper-IgG and IgG autoantibodies in murine systemic lupus erythematosus. Int Immunol 1999; 11: 1685-1691.

32 Ho CY et al. Expression of cyclin B1 and cyclin dependent kinase inhibitor p21 in lymphocytes in patients with systemic lupus erythematosus. J Rheumatol 2002; 29: 2537-2544.

33 Santiago-Raber ML et al. Role of cyclin kinase inhibitor p21 in systemic autoimmunity. J Immunol 2001; 167: 4067-4074.

34 Yasutomo $\mathrm{K}$ et al. Mutation of DNASE1 in people with systemic lupus erythematosus. Nat Genet 2001; 28: 313-314.

35 Walport MJ. Lupus, DNase and defective disposal of cellular debris. Nat Genet 2000; 25: 135-136.

36 Wakeland EK, Liu K, Graham RR, Behrens TW. Delineating the genetic basis of systemic lupus erythematosus. Immunity 2001; 15: 397-408.

37 Lee $\mathrm{SH}$ et al. Decreased tumour necrosis factor-beta production in $\mathrm{TNFB}^{*} 2$ homozygote: an important predisposing factor of lupus nephritis in Koreans. Lupus 1997; 6: 603-609.

38 Jacob CO, McDevitt HO. Tumour necrosis factor- $\alpha$ in murine autoimmune 'lupus' nephritis. Nature 1988; 331: 356-358.
39 Llorente L et al. Role of interleukin 10 in the B lymphocyte hyperactivity and autoantibody production of human systemic lupus erythematosus. J Exp Med 1995; 181: 839-844.

40 Theofilopoulos AN, Kono DH. The genes of systemic autoimmunity. Proc Assoc Am Physicians 1999; 111: 228-240.

41 Fukuyama $\mathrm{H}$ et al. Transgenic expression of Fas in T cells blocks lymphoproliferation but not autoimmune disease in MRL-lpr mice. J Immunol 1998; 160: 3805-3811.

42 Kojima T et al. Analysis of fas ligand gene mutation in patients with systemic lupus erythematosus. Arthritis Rheum 2000; 43: 135-139.

43 Kontoyiannis D, Kollias G. Accelerated autoimmunity and lupus nephritis in NZB mice with an engineered heterozygous deficiency in tumor necrosis factor. Eur J Immunol 2000; 30: 2038-2047.

44 Zhou $\mathrm{T}$ et al. Greatly accelerated lymphadenopathy and autoimmune disease in lpr mice lacking tumor necrosis factor receptor I. J Immunol 1996; 156: 2661-2665.

45 Morimoto $\mathrm{C}$ et al. A defect of immunoregulatory $\mathrm{T}$ cell subsets in systemic lupus erythematosus patients demonstrated with anti2H4 antibody. J Clin Invest 1987; 79: 762-768.

46 Emlen W, Niebur J, Kadera R. Accelerated in vitro apoptosis of lymphocytes from patients with systemic lupus erythematosus. J Immunol 1994; 152: 3685-3692.

47 Goto M, Tanimoto K, Horiuchi Y. Natural cell mediated cytotoxicity in systemic lupus erythematosus: suppression by antilymphocyte antibody. Arthritis Rheum 1980; 23: 1274-1281.

48 Linker-Israeli M, Quismorio Jr FP, Horwitz DA. CD8+ lymphocytes from patients with systemic lupus erythematosus sustain, rather than suppress, spontaneous polyclonal IgG production and synergize with CD4+ cells to support autoantibody synthesis. Arthritis Rheum 1990; 33: 1216-1225.

49 Ohtsuka K et al. Decreased production of TGF-beta by lymphocytes from patients with systemic lupus erythematosus. J Immunol 1998; 160: 2539-2545.

50 Rajagopalan S, Zordan T, Tsokos GC, Datta SK. Pathogenic antiDNA autoantibody-inducing $\mathrm{T}$ helper cell lines from patients with active lupus nephritis: isolation of CD4-8-T helper cell lines that express the gamma delta T-cell antigen receptor. Proc Natl Acad Sci USA 1990; 87: 7020-7024.

51 Horwitz DA et al. Decreased $\mathrm{T}$ cell response to anti-CD2 in systemic lupus erythematosus and reversal by anti-CD28: evidence for impaired T cell-accessory cell interaction. Arthritis Rheum 1997; 40: 822-833.

52 Gray JD, Hirokawa M, Ohtsuka K, Horwitz DA. Generation of an inhibitory circuit involving CD8+ T cells, IL-2, and NK cellderived TGF-beta: contrasting effects of anti-CD2 and anti-CD3. J Immunol 1998; 160: 2248-2254.

53 Stekman IL et al. Enhanced CD3-mediated T lymphocyte proliferation in patients with systemic lupus erythematosus. Arthritis Rheum 1991; 34: 459-467.

54 Sierakowski S, Kucharz EJ, Lightfoot RW, Goodwin JS. Impaired T-cell activation in patients with systemic lupus erythematosus. J Clin Immunol 1989; 9: 469-476.

55 Wong HK, Kammer GM, Dennis G, Tsokos GC. Abnormal NFkappa B activity in T lymphocytes from patients with systemic lupus erythematosus is associated with decreased p65-RelA protein expression. J Immunol 1999; 163: 1682-1689.

56 Hasler P, Schultz LA, Kammer GM. Defective cAMP-dependent phosphorylation of intact $\mathrm{T}$ lymphocytes in active systemic lupus erythematosus. Proc Natl Acad Sci USA 1990; 87: 1978-1982.

57 Solomou EE et al. Molecular basis of deficient IL-2 production in $\mathrm{T}$ cells from patients with systemic lupus erythematosus. J Immunol 2001; 166: 4216-4222.

58 Yi Y, McNerney M, Datta SK. Regulatory defects in $\mathrm{Cbl}$ and mitogen-activated protein kinase (extracellular signal-related kinase) pathways cause persistent hyperexpression of CD40 ligand in human lupus T cells. J Immunol 2000; 165: 6627-6634. 
59 Ohtsuka K, Gray JD, Stimmler MM, Horwitz DA. The relationship between defects in lymphocyte production of transforming growth factor-beta1 in systemic lupus erythematosus and disease activity or severity. Lupus 1999; 8: 90-94.

60 Dau PC, Callahan J, Parker R, Golbus J. Immunologic effects of plasmapheresis synchronized with pulse cyclophosphamide in systemic lupus erythematosus. J Rheumatol 1991; 18: 270-276.

61 Llorente L et al. Clinical and biologic effects of anti-interleukin10 monoclonal antibody administration in systemic lupus erythematosus. Arthritis Rheum 2000; 43: 1790-1800.

62 Traynor AE et al. Treatment of severe systemic lupus erythematosus with high-dose chemotherapy and haemopoietic stem-cell transplantation: a phase I study. Lancet 2000; 356: 701-707.

63 Gottlieb AB, Lahita RG, Chiorazzi N, Kunkel HG. Immune function in systemic lupus erythematosus. Impairment of in vitro T-cell proliferation and in vivo antibody response to exogenous antigen. J Clin Invest 1979; 63: 885-892.

64 Mostoslavsky G et al. Lupus anti-DNA autoantibodies crossreact with a glomerular structural protein: a case for tissue injury by molecular mimicry. Eur J Immunol 2001; 31: 1221-1227.

65 Malkiel S, Kuan AP, Diamond B. Autoimmunity in heart disease: mechanisms and genetic susceptibility. Mol Med Today 1996; 2: 336-342.

66 Hirose $\mathrm{N}$ et al. A role for the polymorphism at position 247 of the beta2-glycoprotein I gene in the generation of anti-beta2glycoprotein I antibodies in the antiphospholipid syndrome. Arthritis Rheum 1999; 42: 1655-1661.

67 Reininger $L$ et al. Intrinsic B cell defects in NZB and NZW mice contribute to systemic lupus erythematosus in $(\mathrm{NZB} \times \mathrm{NZW}) \mathrm{F} 1$ mice. J Exp Med 1996; 184: 853-856.

68 Folzenlogen D et al. Analysis of CD80 and CD86 expression on peripheral blood B lymphocytes reveals increased expression of CD86 in lupus patients. Clin Immunol Immunopathol 1997; 83: 199-204.

69 Takata $\mathrm{M}$ et al. Tyrosine kinases Lyn and Syk regulate B cell receptor-coupled $\mathrm{Ca} 2+$ mobilization through distinct pathways. EMBO J 1994; 13: 1341-1349.

70 Tolnay M, Tsokos GC. Complement receptor 2 in the regulation of the immune response. Clin Immunol Immunopathol 1998; 88: 123-132.

71 D'Ambrosio D et al. Recruitment and activation of PTP1C in negative regulation of antigen receptor signaling by $\mathrm{FC}_{\mathrm{C}}$ gamma RIIB1. Science 1995; 268: 293-297.

72 Liossis SN et al. B-cell kinase lyn deficiency in patients with systemic lupus erythematosus. I Invest Med 2001; 49: 157-165.

73 Mason LJ, Isenberg DA. Immunopathogenesis of SLE. Baillieres Clin Rheumatol 1998; 12: 385-403.

74 Dauphinee MJ, Kipper SB, Wofsy D, Talal N. Interleukin 2 deficiency is a common feature of autoimmune mice. J Immunol 1981; 127: 2483-2487.

75 Alcocer-Varela J, Alarcon-Segovia D. Decreased production of and response to interleukin-2 by cultured lymphocytes from patients with systemic lupus erythematosus. J Clin Invest 1982; 69: 1388-1392.

76 Tada $\mathrm{Y}$ et al. A defect in the protein kinase $\mathrm{C}$ system in T cells from patients with systemic lupus erythematosus. Clin Immunol Immunopathol 1991; 60: 220-231.

77 Phi NC et al. Cyclic AMP level of lymphocytes in patients with systemic lupus erythematosus and its relation to disease activity. Immunol Lett 1989; 23: 61-64.

78 Kammer GM. High prevalence of T cell type I protein kinase A deficiency in systemic lupus erythematosus. Arthritis Rheum 1999; 42: 1458-1465.

79 Tanaka $\mathrm{T}$ et al. Decreased expression of interleukin-2 binding molecules ( $\mathrm{p} 70 / 75)$ in T cells from patients with systemic lupus erythematosus. Arthritis Rheum 1989; 32: 552-559.
80 Liang HE et al. Atypical signaling defects prevent IL-2 gene expression in lpr/lpr CD4-CD8- cells. J Biomed Sci 1998; 5: 297304.

81 Sabzevari H, Propp S, Kono DH, Theofilopoulos AN. G1 arrest and high expression of cyclin kinase and apoptosis inhibitors in accumulated activated/memory phenotype CD4+ cells of older lupus mice. Eur J Immunol 1997; 27: 1901-1910.

82 Gutierrez-Ramos JC et al. Recovery from autoimmunity of MRL/ lpr mice after infection with an interleukin-2/vaccinia recombinant virus. Nature 1990; 346: 271-274.

83 Kelley VE et al. Anti-interleukin 2 receptor antibody suppresses murine diabetic insulitis and lupus nephritis. J Immunol 1988; 140: 59-61.

84 Prud'homme GJ, Kono DH, Theofilopoulos AN. Quantitative polymerase chain reaction analysis reveals marked overexpression of interleukin-1 beta, interleukin-1 and interferon-gamma mRNA in the lymph nodes of lupus-prone mice. Mol Immunol 1995; 32: 495-503.

85 Graninger WB et al. Induction of systemic lupus erythematosus by interferon-gamma in a patient with rheumatoid arthritis. $J$ Rheumatol 1991; 18: 1621-1622.

86 al-Janadi M, al-Balla S, al-Dalaan A, Raziuddin S. Cytokine profile in systemic lupus erythematosus, rheumatoid arthritis, and other rheumatic diseases. J Clin Immunol 1993; 13: 58-67.

87 Jacob CO, van der Meide PH, McDevitt HO. In vivo treatment of $(\mathrm{NZB} \times \mathrm{NZW}) \mathrm{F} 1$ lupus-like nephritis with monoclonal antibody to gamma interferon. J Exp Med 1987; 166: 798-803.

88 Ozmen L et al. Experimental therapy of systemic lupus erythematosus: the treatment of $\mathrm{NZB} / \mathrm{W}$ mice with mouse soluble interferon-gamma receptor inhibits the onset of glomerulonephritis. Eur J Immunol 1995; 25: 6-12.

89 Tokano $Y$ et al. Levels of IL-12 in the sera of patients with systemic lupus erythematosus (SLE)-relation to Th1- and Th2derived cytokines. Clin Exp Immunol 1999; 116: 169-173.

90 Horwitz DA et al. Decreased production of interleukin-12 and other Th1-type cytokines in patients with recent-onset systemic lupus erythematosus. Arthritis Rheum 1998; 41: 838-844.

91 Alleva DG, Kaser SB, Beller DI. Intrinsic defects in macrophage IL-12 production associated with immune dysfunction in the MRL/++ and New Zealand Black/White F1 lupus-prone mice and the Leishmania major-susceptible BALB/c strain. J Immunol 1998; 161: 6878-6884.

92 Huang FP et al. The role of interleukin 12 and nitric oxide in the development of spontaneous autoimmune disease in MRLMPlprlpr mice. J Exp Med 1996; 183: 1447-1459.

93 Houssiau FA et al. IL-12 inhibits in vitro immunoglobulin production by human lupus peripheral blood mononuclear cells (PBMC). Clin Exp Immunol 1997; 108: 375-380.

94 Davas EM et al. Serum IL-6, TNFalpha, p55 srTNFalpha, p75srTNFalpha, srIL-2alpha levels and disease activity in systemic lupus erythematosus. Clin Rheumatol 1999; 18: $17-22$.

95 Swaak AJ, van Rooyen A, Aarden LA. Interleukin-6 (IL-6) and acute phase proteins in the disease course of patients with systemic lupus erythematosus. Rheumatol Int 1989; 8: 263-268.

96 Kroemer G, Martinez C. Cytokines and autoimmune disease. Clin Immunol Immunopathol 1991; 61: 275-295.

97 Casciola-Rosen LA, Anhalt G, Rosen A. Autoantigens targeted in systemic lupus erythematosus are clustered in two populations of surface structures on apoptotic keratinocytes. J Exp Med 1994; 179: $1317-1330$.

98 Kitani A et al. Heterogeneity of $\mathrm{B}$ cell responsiveness to interleukin 4, interleukin 6 and low molecular weight B cell growth factor in discrete stages of B cell activation in patients with systemic lupus erythematosus. Clin Exp Immunol 1989; 77: 31-36.

99 McMurray RW, Hoffman RW, Nelson W, Walker SE. Cytokine mRNA expression in the $\mathrm{B} / \mathrm{W}$ mouse model of systemic lupus 
erythematosus - analyses of strain, gender, and age effects. Clin Immunol Immunopathol 1997; 84: 260-268.

100 Ryffel B et al. Interleukin-6 exacerbates glomerulonephritis in $(\mathrm{NZB} \times \mathrm{NZW}) \mathrm{F} 1$ mice. Am J Pathol 1994; 144: 927-937.

101 Finck BK, Chan B, Wofsy D. Interleukin 6 promotes murine lupus in NZB/NZW F1 mice. J Clin Invest 1994; 94: 585-591.

102 Shirai A, Conover J, Klinman DM. Increased activation and altered ratio of interferon-gamma: interleukin-4 secreting cells in MRL-lpr/lpr mice. Autoimmunity 1995; 21: 107-116.

103 Dueymes $\mathrm{M}$ et al. Relationship of interleukin-4 to isotypic distribution of anti-double-stranded DNA antibodies in systemic lupus erythematosus. Int Arch Allergy Immunol 1993; 101: 408-415.

104 Richaud-Patin Y, Alcocer-Varela J, Llorente L. High levels of TH2 cytokine gene expression in systemic lupus erythematosus. Rev Invest Clin 1995; 47: 267-272.

105 Rus V et al. Expression of cytokine- and chemokine-related genes in peripheral blood mononuclear cells from lupus patients by cDNA array. Clin Immunol 2002; 102: 283-290.

106 Santiago ML et al. Interleukin-4 protects against a genetically linked lupus-like autoimmune syndrome. J Exp Med 1997; 185: 65-70.

107 Hagiwara E, Gourley MF, Lee S, Klinman DK. Disease severity in patients with systemic lupus erythematosus correlates with an increased ratio of interleukin-10: interferon-gamma-secreting cells in the peripheral blood. Arthritis Rheum 1996; 39: 379385.

108 Ishida $\mathrm{H}$ et al. Continuous administration of anti-interleukin 10 antibodies delays onset of autoimmunity in NZB/W F1 mice. $J$ Exp Med 1994; 179: 305-310.

109 Georgescu L, Vakkalanka RK, Elkon KB, Crow MK. Interleukin10 promotes activation-induced cell death of SLE lymphocytes mediated by Fas ligand. I Clin Invest 1997; 100: 2622-2633.

110 Mongan AE, Ramdahin S, Warrington RJ. Interleukin-10 response abnormalities in systemic lupus erythematosus. Scand J Immunol 1997; 46: 406-412.

111 Lacki JK, Samborski W, Mackiewicz SH. Interleukin-10 and interleukin-6 in lupus erythematosus and rheumatoid arthritis, correlations with acute phase proteins. Clin Rheumatol 1997; 16: 275-278.

112 Jacob CO et al. Heritable major histocompatibility complex class II-associated differences in production of tumor necrosis factor alpha: relevance to genetic predisposition to systemic lupus erythematosus. Proc Natl Acad Sci USA 1990; 87: 1233-1237.

113 Mitamura $\mathrm{K}$ et al. Impaired tumour necrosis factor-alpha (TNFalpha) production and abnormal B cell response to TNF-alpha in patients with systemic lupus erythematosus (SLE). Clin Exp Immunol 1991; 85: 386-391.

114 Jones BM, Liu T, Wong RW. Reduced in vitro production of interferon-gamma, interleukin- 4 and interleukin- 12 and increased production of interleukin- 6 , interleukin-10 and tumour necrosis factor-alpha in systemic lupus erythematosus. Weak correlations of cytokine production with disease activity. Autoimmunity 1999; 31: 117-124.

115 Cope AP et al. Chronic tumor necrosis factor alters $\mathrm{T}$ cell responses by attenuating $\mathrm{T}$ cell receptor signaling. J Exp Med 1997; 185: 1573-1584.

116 Tanaka Yet al. Production of B cell-stimulating factors by B cells in patients with systemic lupus erythematosus. J Immunol 1988; 141: 3043-3049.

117 Sierakowski S, Kucharz EJ, Lightfoot Jr RW, Goodwin JS. Interleukin-1-production by monocytes from patients with systemic lupus erythematosus. Clin Rheumatol 1987; 6: 403-407.

118 Brennan DC, Yui MA, Wuthrich RP, Kelley VE. Tumor necrosis factor and IL-1 in New Zealand Black/White mice. Enhanced gene expression and acceleration of renal injury. I Immunol 1989; 143: 3470-3475.
119 Schorlemmer HU, Kanzy EJ, Langner KD, Kurrle R. Immunoregulation of SLE-like disease by the IL-1 receptor: disease modifying activity on BDF1 hybrid mice and MRL autoimmune mice. Agents Actions 1993; 39: C117-C120.

120 Border WA, Ruoslahti E. Transforming growth factor-beta in disease: the dark side of tissue repair. J Clin Invest 1992; 90: $1-7$.

121 Lowrance $\mathrm{JH}$ et al. Spontaneous elaboration of transforming growth factor beta suppresses host defense against bacterial infection in autoimmune MRL/lpr mice. J Exp Med 1994; 180: 1693-1703.

122 Prud'homme GJ, Lawson BR, Theofilopoulos AN. Anticytokine gene therapy of autoimmune diseases. Expert Opin Biol Ther 2001; 1: 359-373.

123 Suarez-Pinzon WL, Rabinovitch A. Approaches to type 1 diabetes prevention by intervention in cytokine immunoregulatory circuits. Int J Exp Diabetes Res 2001; 2: 3-17.

124 Prud'homme GJ, Piccirillo CA. The inhibitory effects of transforming growth factor-beta-1 (TGF-beta1) in autoimmune diseases. J Autoimmun 2000; 14: 23-42.

125 Racke MK et al. Prevention and treatment of chronic relapsing experimental allergic encephalomyelitis by transforming growth factor-beta 1. J Immunol 1991; 146: 3012-3017.

126 Kuruvilla AP et al. Protective effect of transforming growth factor beta 1 on experimental autoimmune diseases in mice. Proc Natl Acad Sci USA 1991; 88: 2918-2921.

$127 \mathrm{Raz}$ E et al. Systemic immunological effects of cytokine genes injected into skeletal muscle. Proc Natl Acad Sci USA 1993; 90: 4523-4527.

128 Piccirillo CA, Chang Y, Prud'homme GJ. TGF-beta1 somatic gene therapy prevents autoimmune disease in nonobese diabetic mice. J Immunol 1998; 161: 3950-3956.

129 Raz E et al. Modulation of disease activity in murine systemic lupus erythematosus by cytokine gene delivery. Lupus 1995; 4: 286-292.

130 Huggins ML et al. Modulation of the autoimmune response in lupus mice by oral administration of attenuated Salmonella typhimurium expressing the IL-2 and TGF-beta genes. Ann NY Acad Sci 1997; 815: 499-502.

131 Huggins ML et al. Modulation of autoimmune disease in the MRL-lpr/lpr mouse by IL-2 and TGF-beta1 gene therapy using attenuated Salmonella typhimurium as gene carrier. Lupus 1999; 8: 29-38.

132 Hagiwara E et al. IL-12-encoding plasmid has a beneficial effect on spontaneous autoimmune disease in MRL/MP-lpr/lpr mice. Cytokine 2000; 12: 1035-1041.

133 Salomon B, Bluestone JA. Complexities of CD28/B7: CTLA-4 costimulatory pathways in autoimmunity and transplantation. Annu Rev Immunol 2001; 19: 225-252.

134 Najafian N, Sayegh MH. CTLA4-Ig: a novel immunosuppressive agent. Expert Opin Invest Drugs 2000; 9: 2147-2157.

135 Takiguchi $\mathrm{M}$ et al. CTLA4IgG gene delivery prevents autoantibody production and lupus nephritis in MRL/lpr mice. Life Sci 2000; 66: 991-1001.

136 Prud'homme GJ, Chang Y. Prevention of autoimmune diabetes by intramuscular gene therapy with a nonviral vector encoding an interferon-gamma receptor/IgG1 fusion protein. Gene Therapy 1999; 6: 771-777.

137 Chang Y, Prud'homme GJ. Intramuscular administration of expression plasmids encoding interferon-gamma receptor/ IgG1 or IL-4/IgG1 chimeric proteins protects from autoimmunity. J Gene Med 1999; 1: 415-423.

138 Prud'homme GJ. Gene therapy of autoimmune diseases with vectors encoding regulatory cytokines or inflammatory cytokine inhibitors. J Gene Med 2000; 2: 222-232.

139 Hartikka J et al. An improved plasmid DNA expression vector for direct injection into skeletal muscle. Hum Gene Ther 1996; 7: 1205-1217. 
140 Theofilopoulos AN, Koundouris S, Kono DH, Lawson BR. The role of IFN-gamma in systemic lupus erythematosus: a challenge to the Th1/Th2 paradigm in autoimmunity. Arthritis Res 2001;3: 136-141.

141 Lawson BR et al. Treatment of murine lupus with cDNA encoding IFN-gammaR/Fc. J Clin Invest 2000; 106: 207-215.
142 Mir LM et al. High-efficiency gene transfer into skeletal muscle mediated by electric pulses. Proc Natl Acad Sci USA 1999; 96: 4262-4267.

143 Krieg AM. CpG motifs in bacterial DNA and their immune effects. Annu Rev Immunol 2002; 20: 709-760. 